\title{
Comparison of the efficacy of extra amniotic Foley catheter, intravaginal prostaglandin E1 tablet and intracervical prostaglandin E2 gel for pre induction cervical ripening: a randomized comparative study
}

\author{
Asha Jenkins ${ }^{1}$, Sendhil Coumary A. ${ }^{2} *$, Seetesh Ghose ${ }^{2}$
}

${ }^{1}$ Civil Surgeon, Tamilnadu Medical services, Nagercoil, Tamilnadu, India

${ }^{2}$ Department of Obstetrics and Gynecology, Mahatma Gandhi Medical College and Research Institute, Puducherry, India

Received: 29 August 2016

Accepted: 28 September 2016

\section{*Correspondence:}

Dr. Sendhil Coumary A.,

E-mail: sendhilcoumary1975@yahoo.in

Copyright: ( $)$ the author(s), publisher and licensee Medip Academy. This is an open-access article distributed under the terms of the Creative Commons Attribution Non-Commercial License, which permits unrestricted non-commercial use, distribution, and reproduction in any medium, provided the original work is properly cited.

\begin{abstract}
Background: To compare the efficacy, efficiency and safety of extra amniotic Foley catheter with intracervical PGE2 gel and intravaginal misoprostol tablet for pre induction cervical ripening. Design of the study was to prospective randomized comparative study. Settings includes, this study was conducted in Mahatma Gandhi Medical College and Research Institute, Puducherry during November 2009 to May 2011.

Methods: Participants for pre induction cervical ripening were randomized to receive either extra amniotic Foley catheter, intravaginal misoprostol tablet $25 \mu \mathrm{g}$ every four hours or intracervical PGE2 gel $0.5 \mathrm{mg}$ every six hours. The post ripening Bishop Score at 12 hours and 24 hours were assessed. The outcome measured was the time taken by the participants to achieve Bishop Score $>5$. The other outcomes included induction ripening interval, induction delivery interval, mode of delivery, requirement of additional agents, maternal and fetal complications.

Results: The post ripening Bishop Score was significantly higher in PGE2 gel group with statistical significance. The induction ripening and the induction delivery interval was significantly shorter in misoprostol tablet group with a ' $p$ ' value $<0.001$. The incidence of NICU admission and other complications like meconium stained liquor, respiratory distress and maternal fever were more associated with misoprostol tablet group.

Conclusions: PGE2 gel is an efficient agent for pre induction cervical ripening when compared to Foley catheter and misoprostol tablet though it is expensive, unstable and requires refrigeration. Tablet misoprostol significantly reduces the ripening duration, ripening delivery interval and the total duration to delivery. Misoprostol tablet is inexpensive, stable at room temperature and easy to administer. It also reduces the need for oxytocin augmentation. However the safety of misoprostol is still a concern due to increased maternal and neonatal complications. Foley catheter alone is not a good cervical ripening agent.
\end{abstract}

Keywords: Cervical ripening, Foley catheter, Misoprostol tablet, PGE2 gel

\section{INTRODUCTION}

The need to time delivery has been recognized and practised for centuries. The indications have clearly changed during the past 200 years, from a need to expel the dead foetus to a pre-emptive action to reduce the threat to foetal or maternal wellbeing. The safe and effective methods of achieving delivery have always been the primary objective.

Cervical 'ripening' is the result of series of complex biochemical process whereby various enzymes stimulate chemical reactions which lead to rearrangement and realignment of collagen fibres leading to cervical 
softening. ${ }^{1} \quad$ It is a physiological process occurring throughout the later weeks of pregnancy and is completed with the onset of labour. When delivery is necessary and ripening has not had time to occur or has failed to be initiated, this natural process has to be accelerated as the condition of the cervix influences the success of induced labour. A cervical assessment is essential before labour induction and the pre induction scoring system is based on properties of the cervix that may be assessed clinically at the time of pelvic examination. ${ }^{2}$

Induction of labour implies stimulation of uterine contractions before the spontaneous onset of labour with or without ruptured membranes. ${ }^{2}$ During the past 40 years, labour induction has mostly involved the recognized advantages of physical manipulation of the cervix with pharmacological myometrial stimulation. The use of a transcervical Foley catheter, a mechanical and non- pharmacological method of cervical ripening has been shown to be an efficient, safe and cost effective method which is associated with a low incidence of uterine contractile abnormalities. It is used in women near term, where delivery is indicated but not urgent. It is preferred when there are contraindications to the use of drugs and it is particularly advantageous in women where prolonged uterine contractions are best avoided like in oligohydramnios, growth restriction and uterine scar.

Misoprostol (Prostaglandin E1 analogue) has recently received attention as a highly effective cervical ripening agent. The advantages are it is less expensive, easy to store and stable at room temperature. Uterine hyper stimulation and meconium stained liquor were seen more frequently with this drug.

Prostaglandin E2 gel (PGE2 gel) has been used for more than a decade for cervical ripening and labour induction and has been approved by FDA. It causes dissolution of collagen bundles and increases the submucosal water content bringing histological changes in the cervix identical to those observed in the early labour. PGE2 gel requires refrigeration for storage.

Literature is available regarding the use of single agent, combination of agents and comparison of two agents also. Studies comparing three methods are not available. This is an attempt to compare the three methods of cervical ripening.

\section{METHODS}

Pregnant women requiring induction of labour between 37 and 41 weeks of gestation with singleton fetus in cephalic presentation with a Bishop score $<5$ and a reactive non stress test were included in the study. Women with prolonged pregnancy or oligohydramnios as indications for induction of labour were included in the present study. Women with any medical or obstetric complications other than prolonged pregnancy or oligohydramnios were excluded from the study. A total of 150 women who fulfilled the study criteria were included and randomised into three groups. The randomisation of participants to the various groups was done using opaque envelopes.

- Group A: Extra amniotic Foley catheter

- Group B: Intravaginal misoprostol tablet

- Group C: Intracervical prostaglandin E2 gel

Participants were involved in the study after taking informed consent and a pre induction Bishop Score was assessed.

In group A, under strict asepsis, 22F Foley catheter was inserted trans-cervically into the extra amniotic space. The balloon was then slowly inflated with the $50 \mathrm{ml}$ of sterile water. The catheter was pulled down such that it was under strain and strapped onto the thigh with the roller gauze. Mobilization was encouraged. The Bishop score was reassessed on spontaneous expulsion. In the absence of spontaneous expulsion, the catheter was deflated, removed and the cervix re-assessed 12 hours post-insertion.

In group $\mathrm{B}$, misoprostol 25 microgram tablets were placed intra vaginally in the posterior fornix. The dose was repeated every 4 hours with a maximum of three doses. Bishop score was assessed after 12 hours if the patient was not in established labour.

In group C, PGE2 gel 0.5 milligram was applied intracervically twice for a maximum of 2 doses six hours apart. The bishop score was re assessed after 12 hours post application.

The improvement in Bishop Score was noted at 12 hours for all the participants. If it was less than 5/13 in any of the groups, further induction was carried as per the consultant's discretion and the previous method used. Patients were followed up through delivery and immediate postpartum period. All the cases were monitored by using a partograph. The outcome in the mother and baby were noted. The following parameters were noted:

1. The Bishop score at 12 hours

2. The number of participants who achieved a Bishop score $>5$ in 12 hours

3. The time taken for ripening

4. The ripening to delivery interval

5. The total duration to delivery

6. The mode of delivery

7. The need for additional drugs to achieve Bishop score of 5

8. Adverse outcomes like abnormal uterine contractions and low Apgar scores were noted.

Statistical analysis was performed using SPSS statistical package. The results were tabulated, analysed and 
compared with ANOVA test and Fischer test. A p value of $<0.05$ was considered statistically significant.

\section{RESULTS}

The demographic parameters like maternal age, parity, gestational age and the percentage of women in each group for the various indications for induction of labour are as shown in Table 1. The demographic parameters were comparable among the three groups.

Table: 1 Demographic variables and indication for induction.

\begin{tabular}{|c|c|c|c|}
\hline Parameters & Group A & Group B & Group C \\
\hline $\begin{array}{l}\text { 1) Mean age } \\
\text { in years }\end{array}$ & $24.24 \pm 3.66$ & $23.74 \pm 3.28$ & $24.18 \pm 3.65$ \\
\hline \multicolumn{4}{|l|}{ 2) Parity } \\
\hline Primigravida & $74 \%$ & $62 \%$ & $72 \%$ \\
\hline Multigravida & $26 \%$ & $38 \%$ & $28 \%$ \\
\hline \multicolumn{4}{|c|}{ 3) Gestationalage (wks) } \\
\hline $37-40$ & $42 \%$ & $40 \%$ & $46 \%$ \\
\hline $40-41$ & $58 \%$ & $60 \%$ & $54 \%$ \\
\hline \multicolumn{4}{|c|}{ 4) Indication for Induction } \\
\hline $\begin{array}{l}\text { Oligohydra } \\
\text { mnios }\end{array}$ & $62 \%$ & $60 \%$ & $60 \%$ \\
\hline $\begin{array}{l}\text { Prolonged } \\
\text { pregnancy }\end{array}$ & $38 \%$ & $40 \%$ & $40 \%$ \\
\hline
\end{tabular}

The pre ripening bishop score was $2.34 \pm 0.63,2.76 \pm 0.82$ and $2.24 \pm 0.74$ in groups $\mathrm{A}, \mathrm{B}$ and $\mathrm{C}$ respectively. The post ripening bishop score was $5.78 \pm 1.82,6.08 \pm 1.89$ and $7.17 \pm 2.77$ in groups $\mathrm{A}, \mathrm{B}$ and $\mathrm{C}$ respectively. Comparing these three groups, the difference in pre and post ripening bishop score using ANOVA test, group $\mathrm{C}$ had higher post ripening Bishop Score, the $\mathrm{p}$ value being 0.019 which was statistically significant (Table 2, Figure 1). The post ripening Bishop score at the end of twelve hours was less than 5 in $42.85 \%, 33.33 \%$ and $15.15 \%$ of patients in groups $\mathrm{A}, \mathrm{B}$ and $\mathrm{C}$ respectively. Post ripening Bishop Score was more than 5 in $57.14 \%, 66.66 \%$ and $75.75 \%$ in groups $\mathrm{A}, \mathrm{B}$ and $\mathrm{C}$ respectively. The percentage of patients who delivered prior to the assessment of Bishop Score at 12 hours was $2 \%, 28 \%$ and $30 \%$ of patients in groups $\mathrm{A}, \mathrm{B}$ and $\mathrm{C}$ respectively. In group $\mathrm{C}, 8 \%$ of the patients had post ripening Bishop Scores between 11 and 13.

Table: 2 Comparisons of pre and post ripening BISHOP score.

\begin{tabular}{|llll|}
\hline $\begin{array}{l}\text { BISHOP } \\
\text { score }\end{array}$ & $\begin{array}{l}\text { Group A } \\
\text { (Foleys } \\
\text { catheter) }\end{array}$ & $\begin{array}{l}\text { Group B } \\
\text { (PgE1 } \\
\text { tablet) }\end{array}$ & $\begin{array}{l}\text { Group C } \\
\text { (PgE2 gel) }\end{array}$ \\
\hline Pre- ripening & $2.34 \pm 0.63$ & $2.76 \pm 0.82$ & $2.24 \pm .74$ \\
\hline Post- ripening & $5.78 \pm 1.82$ & $6.08 \pm 1.89$ & $7.17 \pm 2.77$ \\
\hline P Value & $0.019^{*}$ & & \\
\hline
\end{tabular}

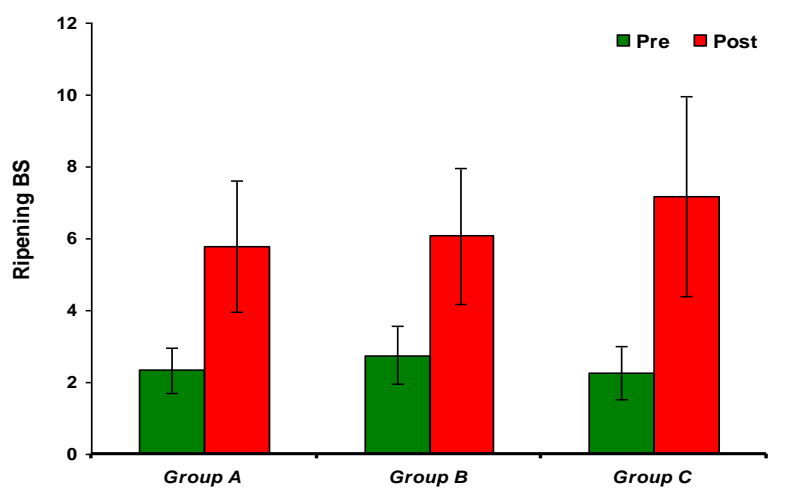

Figure: 1 Comparison of pre and post ripening BISHOP score.

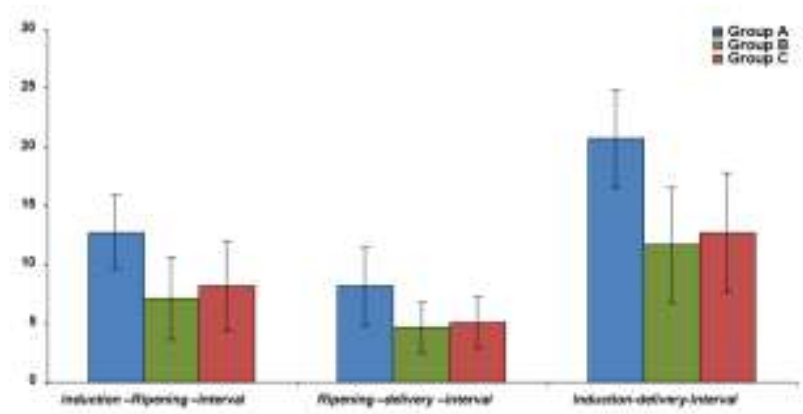

Figure: 2 Comparison of ripening duration, ripeningdelivery and total duration.

The initiation to ripening interval otherwise known as the time taken to ripening was $12.77 \pm 3.11$ hours, $7.14 \pm 3.53$ hours and $8.16 \pm 3.79$ hours in groups $\mathrm{A}, \mathrm{B}$ and $\mathrm{C}$ respectively. The mean ripening to delivery interval was $8.14 \pm 3.37$ hours, $4.68 \pm 2.17$ hours and $5.07 \pm 2.15$ hours in groups $\mathrm{A}, \mathrm{B}$ and $\mathrm{C}$ respectively. The total duration to delivery was $20.71 \pm 4.12$ hours, $11.65 \pm 4.95$ hours and $12.74 \pm 5.09$ hours in groups $\mathrm{A}, \mathrm{B}$ and $\mathrm{C}$ respectively. On comparing these three groups, the initiation to ripening, the ripening to delivery and the total duration to delivery interval was the shortest in group $\mathrm{B}$, with a $\mathrm{p}$ value of $<0.001$ which was statistically significant (Table 3).

Table 3: Comparison of ripening duration, ripeningdelivery and induction-delivery intervals.

\begin{tabular}{|lllll|}
\hline Parameters & $\begin{array}{l}\text { Group A } \\
\text { (Foleys } \\
\text { catheter) }\end{array}$ & $\begin{array}{l}\text { Group B } \\
\text { (PgE1 } \\
\text { tablet) }\end{array}$ & $\begin{array}{l}\text { Group C } \\
\text { (PgE2 gel) }\end{array}$ & $\begin{array}{l}\text { P } \\
\text { value }\end{array}$ \\
\hline $\begin{array}{l}\text { Ripening } \\
\text { duration }\end{array}$ & $12.77 \pm 3.11$ & $7.14 \pm 3.53$ & $8.16 \pm 3.79$ & $<0.001$ \\
\hline $\begin{array}{l}\text { Ripening- } \\
\text { delivery }\end{array}$ & $8.14 \pm 3.37$ & $4.68 \pm 2.17$ & $5.07 \pm 2.15$ & $<0.001$ \\
\hline $\begin{array}{l}\text { Total } \\
\text { duration }\end{array}$ & $20.71 \pm 4.12$ & $11.65 \pm 4.95$ & $12.74 \pm 5.09$ & $<0.001$ \\
\hline
\end{tabular}

The requirement of additional agents for further ripening and augmentation of labour was more associated with group A when compared to groups B and C. Comparison 
of the modes delivery among three groups of patients did not show any statistical significance (Table 4).

Table 4: Other parameters studied and neonatal outcomes.

\begin{tabular}{|c|c|c|c|}
\hline Parameters & $\begin{array}{l}\text { Group A } \\
\text { (Foleys } \\
\text { catheter) }\end{array}$ & $\begin{array}{l}\text { Group B } \\
\text { (PgE1 } \\
\text { tablet) }\end{array}$ & $\begin{array}{l}\text { Group C } \\
\text { (PgE2 gel) }\end{array}$ \\
\hline \multicolumn{4}{|l|}{ Additional agents } \\
\hline Oxytocin & $\begin{array}{l}41 \\
(83.7 \%)\end{array}$ & $\begin{array}{l}29 \\
(65.9 \%)\end{array}$ & $32(66.6 \%)$ \\
\hline \multicolumn{4}{|l|}{ Mode of delivery } \\
\hline Vaginal delivery & $31(62 \%)$ & $31(62 \%)$ & $40(80 \%)$ \\
\hline Forceps & $3(6.0 \%)$ & $3(6.0 \%)$ & $0.0 \%$ \\
\hline LSCS & $\begin{array}{l}16 \\
(32.0 \%)\end{array}$ & $\begin{array}{l}16 \\
(32.0 \%)\end{array}$ & $10(20.0 \%)$ \\
\hline \multicolumn{4}{|l|}{ Neonatal outcome } \\
\hline \multicolumn{4}{|l|}{ APGAR at $5 \mathrm{~min}$} \\
\hline$<7$ & $1(2.0 \%)$ & $2(4.0 \%)$ & $1(2.0 \%)$ \\
\hline$>7$ & $\begin{array}{l}49 \\
(98.0 \%)\end{array}$ & $\begin{array}{l}48 \\
(96.0 \%)\end{array}$ & $49(98.0 \%)$ \\
\hline NICU admission & $2(4.0 \%)$ & $\begin{array}{l}15 \\
(30.0 \%)\end{array}$ & $3(6.0 \%)$ \\
\hline
\end{tabular}

The one minute Apgar $<7$ in groups $\mathrm{A}, \mathrm{B}$ and $\mathrm{C}$ were $10 \%, 36 \%$ and $14 \%$ respectively. On comparing the three groups with ANOVA and Fisher exact test, the Apgar score $<7$ at the first minute was more in group B when compared to groups $\mathrm{A}$ and $\mathrm{C}$ with a $\mathrm{p}$ value of 0.002 which was of statistical significance. When comparing the Apgar score at five minutes, only $2 \%$ in group A, $4 \%$ in group B and 2\% in group $\mathrm{C}$ had an Apgar score $<7$ with a $\mathrm{p}$ value of 1.000 which was not statistically significant. When comparing the NICU admissions among the three groups, $4 \%, 30 \%$ and $6 \%$ in groups A, B and $\mathrm{C}$ required NICU admissions for various indications. The incidence of NICU admissions in group B was more; the $\mathrm{p}$ value was $<0.001$ which was statistically significant. The incidence of other complications like meconium stained liquor, respiratory distress and maternal fever were more in group B (38\%) when compared to group A (32\%) and group C (8\%). The p value was 0.001 which was statistically significant (Table 4).

\section{DISCUSSION}

Labour is often induced for several maternal and fetal indications. Pre induction cervical ripening is done to avoid prolonged or failed inductions. The present study was conducted in Mahatma Gandhi Medical College and Research Institute, Puducherry, a tertiary care centre during November 2009 to May 2011, to compare the efficacy of extra amniotic Foley catheter, intravaginal misoprostol tablet and intracervical $\mathrm{PGE}_{2}$ gel for preinduction cervical ripening. A total of 150 women were selected and randomized into three groups as mentioned earlier.
In the present study the inclusion criteria was a pre ripening Bishop Score <5. The indication for cervical ripening was restricted to oligohydramnios at and prolonged pregnancy up to 41 weeks. Manjunath AP et al in their study comparing misoprostol and PGE2 included women with a Bishop score of less than 5 in both the groups. Their study included all women with an obstetric or medical indication for delivery after 37 weeks. ${ }^{3}$ Ayaz A, et al conducted a study to compare vaginal misoprostol with vaginal dinoprostone. They included women with a bishop score of less than 6 between 40-42 weeks without a uterine scar. ${ }^{4}$ A Bishop score of less than 4 at term in women requiring induction of labour was the inclusion criteria in the study by Tabowei et al who compared intracervical Foley with misoprostol..$^{5}$ They only excluded women who had contraindications to vaginal delivery and prelabour rupture of membranes. Tabowei et al included women with prior lower segment scar in both the groups. In a study by Vahid Roudsari F et al conducted in Iran comparing intracervical Foley with intravaginal misoprostol. ${ }^{6}$ Their inclusion criterion was women beyond 37 weeks of gestation requiring induction of labour having a bishop score of less than 6. In the study by Henry et al in an Australian tertiary hospital, intracervical Foley balloon was compared with intracervical dinoprostone among women with a need for cervical ripening and Bishop Score of less than seven. ${ }^{7}$ Kosinka et al compared intracervical Foley with intracervical dinoprostone at a University hospital in Poland. ${ }^{8}$ They included women with a bishop score of less than six. Most of the studies in the literature had similar inclusion and exclusion criteria though the route of administration of dinoprostone varied.

In the present study the post ripening Bishop Score was $5.78 \pm 1.82,6.08 \pm 1.89$ and $7.17 \pm 2.77$ in the groups A, B and $\mathrm{C}$ respectively. On comparing the three groups, the post ripening Bishop Score was significantly higher in group C (Misoprostol group) with a $\mathrm{P}$ value of 0.019 . In the Manjunath AP et al study, the mean post ripening Bishop Score after 12 hours was $5.95 \pm 1.59$ in misoprostol group and $5.95 \pm 2.78$ in PGE2 group, which was not a statistically significant difference. ${ }^{3}$ The mean bishop score post ripening was not mentioned in the study by A Ayaz et al. ${ }^{4}$ In the study by Niromanesh et al, the effectiveness of intracervical Foley catheter and PGE2 tablets for cervical ripening were compared. The mean post ripening Bishop Score in Foley catheter group was $6.6 \pm 0.80$ and in $\mathrm{PGE}_{2}$ group was $6.7 \pm 0.86$. There was no difference between the mean Bishop score between the two groups. ${ }^{9}$ Tabowei et al in their study showed that intravaginal misoprostol was more effective than intracervical Foley catheter in producing cervical ripening. ${ }^{5} 61 \%$ of women achieved a favourable Bishop score within 12 hours in the misoprostol group when compared to $38 \%$ in the Foley catheter group. Vahid Roudsari $\mathrm{F}$ et al also did not mention about the post ripening bishop score in their study. ${ }^{6}$ Henry et al and Kosinka et al did not include post ripening bishop score as a variable for analysis in their study. ${ }^{7,8}$ However, as 
Bishop Score is very subjective, a more objective method of cervical ripening assessment should be used to overcome observer related bias.

In the present study, the total duration to delivery from initiation of ripening was $20.71 \pm 4.12,11.65 \pm 4.95$ and 12.74 \pm 5.09 hours in the Foley, misoprostol and PGE2 groups respectively. It was significantly shorter in misoprostol group when compared to the other two groups with a $\mathrm{P}$ value $<0.001$. In the Manjunath AP et al study, the induction delivery interval was less than 12 hours in $51.3 \%$ of the women in misoprostol group and $53.8 \%$ in PGE2 group. ${ }^{3} 31.1 \%$ and $35.5 \%$ of women in both the groups delivered between 12 to 24 hours. $17.6 \%$ and $10.9 \%$ of women in the two groups delivered after 24 hours. There was no significant difference in the median induction to vaginal delivery interval in both the groups. In the study by A Ayaz et al the mean time from induction to onset of significant uterine contractions was 6.1 hours in misoprostol group and 7.2 hours in the dinoprostone group $(\mathrm{p}=0.16){ }^{4}$ However, the mean time from induction to delivery was 8.2 hours in the misoprostol group and 11.0 hours in the dinoprostone group ( $\mathrm{p}=0.007)$. Induction failed in 18 subjects $(30 \%)$ in the dinoprostone Group and only failed in two (3\%) in the misoprostol group $(\mathrm{p}<0.001)$. In Tabowei et al study, the median induction delivery interval was significantly shorter in misoprostol group (22.7 \pm 7.1 hours) when compared to Foley catheter group ( $31.3 \pm 8.0$ hours) with a $\mathrm{P}$ value $<0.001 .^{5}$ In the study by Vahid Roudsari $\mathrm{F}$ et al the mean of time to delivery was $11.08 \pm 5.6 \mathrm{~h}$ in the misoprostol group, and $13.6 \pm 16.9 \mathrm{~h}$ in Foley the group and it was significantly shorter in the misoprostol group $(\mathrm{p}<0.05) .^{6}$ In the study by Henry et al the mean induction to delivery interval was 33.5 hours in the Foley group and 31.1 hours in the dinoprostone group, which was not statistically significant $(\mathrm{p}=0.402){ }^{7}$ Kosinka et al in their study mentioned the initiation of ripening to delivery interval in minutes. ${ }^{8}$ It was $1682 \pm 2387$ minutes in the Foley group and $920 \pm 600$ minutes in the intracervical dinoprostone group. The difference was statistically significant with a $\mathrm{p}$ value of $<0.001$.

In the present study, though the post ripening Bishop Score was greater in PGE2 gel group, the time taken to deliver was shorter in misoprostol group. This is primarily due to the pharmacokinetic profile of the vaginal misoprostol. Though the bioavailability is greater with oral administration of misoprostol, vaginal route causes regular uterine contractility nearly four hours following its administration through locally mediated action and affects a faster delivery. The cervical change associated with the use of misoprostol is due to its dual action. It increases the uterine contractions which causes secondary cervical changes and also direct biochemical changes in the cervix mainly disintegration of cervical collagen. ${ }^{10}$

PGE2 is one of the prostanoids which is associated with inflammation. It markedly enhances edema and leucocyte infiltration by promoting blood flow. ${ }^{11}$ Labour, as we know is an inflammatory process where the collagenolysis is caused by an influx of inflammatory cells and in part by fibroblast cells. All these changes make the cervix soft, pliable and easy to dilate. Thus, PGE2 acts as a better ripening agent than misoprostol. PGE2 also induces uterine contractions when given in low doses however higher concentrations will cause uterine relaxation. The contractions induced by PGE2 are physiological. ${ }^{12}$

In the present study, the rate of vaginal delivery was $62 \%$ in Foley and misoprostol group respectively where as it was $80 \%$ in PGE2 group. The rate of caesarean delivery was $32 \%$ in the Foley catheter and misoprostol groups respectively, whereas it was only $20 \%$ in the PGE2 group. The incidence of instrumental delivery was $6 \%$ in Foley and misoprostol group. There were no instrumental deliveries in PGE2 group. The incidence of vaginal delivery was more in PGE2 group when compared to the misoprostol and Foley groups. The incidence of caesarean section was more in Foley catheter and misoprostol group. Patients in misoprostol group had caesarean section mostly due to fetal distress. The high incidence of caesarean section in the present study could be attributed to the indications of induction being mainly oligohydramnios and prolonged pregnancy. In the Manjunath AP et al study, $67.9 \%$ of women in misoprostol group and $66.5 \%$ of women in PGE2 group delivered vaginally. $6.9 \%$ and $7.5 \%$ of women had instrumental vaginal delivery whereas $25.2 \%$ and $26.1 \%$ of women underwent caesarean section, the common indication being fetal distress. No difference was noted in the overall incidence of the mode of delivery in both the groups. Regarding the modes of delivery in the study by A Ayaz et al, 42 women (70\%) in the misoprostol group had spontaneous vaginal deliveries, $14(23 \%)$ had instrumental vaginal deliveries, and four $(6 \%)$ required CS. In the dinoprostone group, only $26(43 \%)$ delivered vaginally, while $16(27 \%)$ required instrumental vaginal deliveries and $18(30 \%)$ required CS (overall $\mathrm{p}=0.002$ ). The methodology of A Ayaz study is to give $3 \mathrm{mg}$ of dinoprostone vaginally every six hours. It is understood by the pharmacokinetics of dinoprostone that only lower doses are efficacious in ripening and higher doses cause uterine relaxation, this the probable reason why dinoprostone failed as an inducing agent in their study. In the study Tabowei et al $65 \%$ of the women in misoprostol group and $59 \%$ of women in the Foley catheter group delivered vaginally. ${ }^{5} 21.7 \%$ and $24.6 \%$ in both the groups had operative vaginal delivery. $13.3 \%$ and $16.4 \%$ of the women in the two groups underwent caesarean section. No statistically significant difference existed in the mode of delivery. In the study by Vahid Roudsari $F$ et al the rate of vaginal delivery in the misoprostol group was $89.8 \%$ and in the foley group was $62.7 \%$. The rate of vaginal delivery was significantly higher in misoprostol group ( $\mathrm{p}<0.01)$. In the study by Henry et al, $66 \%$ of women in the foley group and $71 \%$ of women in the PGE2 group delivered vaginally. The incidence of 
instrumental delivery was higher in the foley group (36\%) compared to the PGE2 group (22\%), though not statistically significant. The cesearean delivery rates were high in both the groups (34\% and $29 \%$ ) respectively. In the study by Kosinka et al, $68.6 \%$ of patients in the foley group and $65.6 \%$ of patients in the intracervical dinoprostone gel group delivered vaginally and the difference was not statistically significant ( $p$ value= $0.65)$.

In the study by Manjunath AP et al, the oxytocin requirement was similar in both the groups. The study by A Ayaz et al does not speak about usage of oxytocin to augment contractions if contractions are inadequate after ripening. In the study by T.O Tabowei et al, the need for Oxytocin in misoprostol and Foley catheter group were $73 \%$ and $95 \%$ respectively. ${ }^{5}$ The Oxytocin requirement was less in misoprostol group when compared to Foley catheter group, which was statistically significant. Though the methodology speaks about usage of oxytocin if contractions are inadequate, in the study by Vahid Roudsari F et al the usage of oxytocin was not analysed. In the present study, $83.7 \%$ in Foley catheter group, $65.9 \%$ in misoprostol group and $66.66 \%$ in PGE2 gel group required oxytocin. The percentage of patients requiring oxytocin was significantly more in Foley catheter group, because it only served as a mechanical dilator and did not induce contractions efficiently like misoprostol or the PGE2 gel. $47.4 \%$ of patients in the Foley group and $43.6 \%$ of patients in the intracervical dinoprostone gel group required administration of oxytocin in either the first stage or second stage of labour. There was no difference between the two groups $(\mathrm{p}=0.93)$.

In Manjunath AP et al study, 9.4\% of the new-borns in misoprostol group and $8 \%$ in PGE2 gel group had an Apgar score of less than seven at one minute. Apgar score of less than seven at five minutes was seen in $1.8 \%$ and $0.6 \%$ of the new-borns in both the groups respectively. There was one NICU admission $(0.6 \%)$ in $\mathrm{PGE}_{2}$ group. There was no statistical difference in the Apgar scores and the NICU admissions in both the groups. In the study by A Ayaz et al there was more number of new-borns with lower Apgar scores and admission to NICU in the misoprostol group than the dinoprostone group, though this was not statistically significant. Tabowei et al study also reflected similar reports showing increased admissions to NICU and lower Apgar scores in the misoprostol group than the Foley group, though not statistically different. ${ }^{5}$ Vahid Roudsari $F$ et al showed no that there was no difference in the neonatal outcomes in both the foley and the misoprostol group. In the study by Henry et al, there was no difference in the neonatal outcomes (Apgar score and NICU admission) between the two groups. In the study by Kosinka et al more children were born with a better Apgar score at the first minute in the Foley group in comparison to the intracervical gel group $(98.1 \%$ vs $89.2 \%, \mathrm{p}=0.009$ ) however the five minute Apgar score was the same in both the groups. In the present study, $36 \%, 10 \%$ and $14 \%$ of the new-borns in misoprostol, Foley and PGE2 groups had an Apgar score of less than seven at the first minute. Comparing the three groups, the percentage of neonates with low Apgar scores at one minute was more in the $B$ group ( $P$ value 0.002 ) which was statistically significant. Thirty percentage of the neonates in the misoprostol group required NICU admission when compared to $4 \%$ and $3 \%$ in the Foley and $\mathrm{PGE}_{2}$ group with a $\mathrm{p}$ value of $<0.001$ which was statistically significant. The high rate of NICU admissions were due to meconium stained liquor. There was no neonatal mortality in the present study.

The limitations of the present study were its sample size and the variation in subjective assessment of the cervix. As the comparison involves three different methods of ripening, larger sample size will be required to justify the results.

\section{CONCLUSION}

Extra amniotic Foley catheter which is a mechanical method of ripening was not as efficient as $\mathrm{PGE}_{2}$ gel or misoprostol tablet in ripening the cervix. It is less expensive with no storage specifications but it requires a skilled person to insert the Foley. In the present study, PGE2 gel is an efficient agent for pre induction cervical ripening when compared to Foley catheter and misoprostol tablet. PGE2 gel is expensive, unstable and requires refrigerated storage. Misoprostol tablet significantly reduces the ripening duration, ripening delivery interval and total duration to delivery. misoprostol tablet is inexpensive, stable at room temperature and easy to administer. It also reduces the need for oxytocin augmentation. However the safety of misoprostol is still a concern, because of frequent meconium staining of liquor, low Apgar scores and need for NICU admissions though it did not cause any major adverse neonatal outcome. The need for caesarean section was similar in all the three groups. A judicious selection of prostaglandins according to the Bishop score and the indication of induction would yield the best results, considering both are safe and effective.

\section{ACKNOWLEDGEMENTS}

The authors would like to thank the Chairman, vice chancellor, Prof. Ananthakrishnan and the labour room team for the constant support and encouragement throughout the study period.

\section{Funding: No funding sources}

Conflict of interest: None declared

Ethical approval: The study was approved by the Institutional Ethics Committee 


\section{REFERENCES}

1. Lenova C, Spong B, Hoffman D. Williams obstetrics. $24^{\text {th }}$ edition, Mc Graw Hill; Physiology of labour. 2014:408-431.

2. Lenova C, Spong B, Hoffman D. Williams obstetrics. $24^{\text {th }}$ edition, Mc Graw Hill; Induction and augmentation of labour. 2014:523-534.

3. Shivarudraiah G, Palaksha MA. The Journal of Obstetrics and Gynaecology of India. 2011:153-60.

4. Aqueela A, Shaukat S, Farooq MU, Khalid M, Iftikhar A, Muhammad LAB. Induction of labor: a comparative study of intravaginal misoprostol and dinoprostone. Taiwan J Obstet Gynecol. 2010;49:2.

5. Tabowei TO, Oboro VO. Low dose intravaginal misoprostol versus intracervical baloon catheter for pre-induction cervical ripening. East Afr Med J. 2003;80(2):91-4.

6. Roudsaria FV, Sedigheh A, Marzieh G, Maliheh HM, Shakerib MT. Comparison of Vaginal Misoprostol with Foley Catheter for Cervical Ripening and Induction of Labor. Iranian Journal of Pharmaceutical Research. 2011;10(1):149-54.

7. Henry A, Madan A, Reid R, Tracy SK, Kathryn A, Alec W, et al. Outpatient Foley catheter versus inpatient prostaglandin E2 gel for induction of labour: a randomised trial BMC Pregnancy and Childbirth $2013 ; 13: 25$ http://www.biomedcentral.com/1471-2393/13/25
8. Kosinska-Kaczynska K, Piotr C, Aleksandra S, Iwona S, Miroslaw W. Two methods of cervix ripening: intracervical Foley catether and dinoprostone- which one is actually more efficient? Neuroendocrinology Letters. 2015;36(3).

9. Niromanesh S, Mosavi-Jarrahi A, Samkhaniani F. Intracervical Foley catheter balloon vs. prostaglandin in preinduction cervical ripening. Int $\mathrm{J}$ Gynaecol Obstet. 2003;81(1):23-7.

10. Tang OS, Gemzell-Danielsson K, Ho PC. Misoprostol: pharmacokinetic profiles, effects on the uterus and side-effects. Int $\mathbf{J}$ Gynaecol Obstet. 2007;99(2):S160-7.

11. Emer M. Smyth and Garret A. Fitzgerald. The eicosanoids: prostaglandins, thromboxanes, leucotrienes and related compounds. In Betram G. Katzung editor, Basic and clinical pharmacology, 11th edition Mc Graw Hill publishing; 2009.

12. Jane E. Norman. Induction of labour. In Brian A Magowan editor, clinical Obstetrics and Gynecology, 3rd edition Saunders Elsevier publishing; 2014.

Cite this article as: Jenkins A, Sendhil CA, Ghose S. Comparison of the efficacy of extra amniotic Foley catheter, intravaginal prostaglandin E1 tablet and intracervical prostaglandin E2 gel for pre induction cervical ripening: a randomized comparative study. Int J Reprod Contracept Obstet Gynecol 2016;5:3902-8. 